\title{
PERANCANGAN SISTEM INFORMASI BERBASIS WEB PENGELOLAAN INVENTARIS ASET KANTOR DI PT. MPM FINANCE BANDUNG
}

\author{
Johni S Pasaribu \\ Program Studi Teknik Informatika, Fakultas Information \& Technology \\ Politeknik Piksi Ganesha \\ Jln Gatot Subroto 301 Bandung \\ johni_0106@yahoo.com,johni.s.pasaribu@piksi.ac.id
}

\begin{abstract}
Abstrak
Perangkat lunak atau software merupakan suatu perintah program yang terdapat di dalam sebuah komputer dimana ketika dieksekusi oleh usernya akan memberikan sejumlah fungsi sekaligus menampilkan informasi yang diinginkan oleh usernya sesuai kebutuhan yang dibuat sebelumnya. PT. MPM Finance Bandung merupakan perusahaan swasta yang bergerak dalam bidang jasa peminjaman keuangan yang berlokasi di Jl. BKR No.26A, Cijagra, Kec. Lengkong, Kota Bandung, Jawa Barat 40265. Setiap instansi atau lembaga baik pemerintah maupun swasta pasti memiliki barang inventaris kantor seperti meja, kursi, komputer, laptop, mobil, motor, dan sebagainya. Barang inventaris adalah daftar yang memuat semua barang milik kantor yang dipakai untuk melaksanakan tugas instansi atau lembaga tersebut. Demikian pula halnya dengan PT. MPM Finance Bandung tidak terlepas dari persoalan inventaris yaitu pengolahan data inventaris masih dilakukan secara manual, yakni belum menggunakan database sebagai penyimpanan data, serta membutuhkan waktu yang lama dalam mengolah data karena data inventaris yang terdaftar tersebut bila dimasukkan ke komputer memakai Microsoft Excel tanpa menggunakan database. Pemanfaatan perangkat lunak dalam pembuatan sistem informasi untukpengelolaan inventaris diperlukan agar dapat membantu pengumpulan dan pengolahan inventaris dan dapat memudahkan proses pelaporan dan penyimpanan data inventaris serta meminimalisir terjadinya kesalahan manusia. Metode yang digunakan dalam pengembangan sistem informasi ini adalah model Waterfall. Output yang dihasilkan yaitu aplikasi yang membantu melakukan konfigurasi, pendataan, penjumlahan, status aset serta pembuatan laporan informasi aset perusahaan dan letak aset tersebut.
\end{abstract}

Kata kunci: Sistem Informasi, Pengelolaan Inventaris, Berbasis Web, Metode Waterfall

\begin{abstract}
Software is a program command contained in a computer where when executed by the user it will provide a number of functions while displaying the information desired by the user according to the previously created needs. PT. MPM Finance Bandung is a private company engaged in financial lending services located on Jl. BKR No.26A, Cijagra, Kec. Lengkong, Bandung City, West Java 40265. Every government or private agency or institution must have office inventory items such as tables, chairs, computers, laptops, cars, motorcycles, and so on. Inventory is a list containing all office property used to carry out the duties of the agency or institution. Likewise with PT. MPM Finance Bandung is inseparable from inventory problems, namely inventory data processing is still done manually, which is not yet using a database as data storage, and it takes a long time to process data because the registered inventory data is entered into a computer using Microsoft Excel without using a database. Utilization of software in the manufacture of information systems for inventory management is needed in order to assist the collection and processing of inventory and can facilitate the process of reporting and storing inventory data and minimizing the occurrence of human errors. The method used in the development of this information system is the Waterfall model. The resulting output is an application that helps configure, collect data, add up, status of assets and make reports on company asset information and the location of these assets.
\end{abstract}


Keywords: Information System, Inventory Management, Web-based, Waterfall Method

\section{Pendahuluan}

Dewasa ini penerapan sistem informasi sangat dibutuhkan baik pada instansi pemerintah maupun swasta. Hal ini karena dengan adanya perkembangan teknologi yang sangat pesat ini menuntut agar suatu instansi memperoleh informasi yang cepat dan akurat. Sistem informasi tentunya akan membuat kinerja suatu instansi terlaksana lebih baik dan dapat melakukan berbagai pengolahan data dengan menggunakan teknologi informasi dan komunikasi.

Sistem informasi dibuat untuk memudahkan dalam pengelolaan dan penyimpanan data sehingga akan dapat menghasilkan suatu informasi yang tepat dan akurat. Adanya informasi yang tepat dan akurat tersebut maka dapat mengurangi terjadinya kesalahan yang tidak diinginkan sehingga dapat meningkatkan kinerja yang lebih efisien dan kecepatan operasional instansi.

PT. MPM Finance merupakan perusahaan pembiayaan untuk memenuhi berbagai kebutuhan masyarakat, mulai dari kepemilikan kendaraan bermotor, pemenuhan modal kerja, perjalanan wisata, pendidikan, pernikahan, hingga pengadaan mesin dan alat-alat berat untuk kebutuhan usaha. Untuk mendukung kinerja perusahaan maka dibutuhkan inventaris barang untuk bisa digunakan dalam bekerja seperti perlengkapan kantor, laptop/PC, printer, kendaraan, dan lain sebagainya. Dari observasi serta wawancara yang dilakukan, terdapat data inventaris barang yang belum mempunyai sistem komputerisasi, selain itu pengolahan data inventaris masih dilakukan secara manual yakni belum menggunakan database sebagai penyimpanan data. Sehingga nantinya membutuhkan waktu yang lama dan tenaga dimana data inventaris tersebut harus dimasukkan ke dalam komputer memakai Microsoft Excel tanpa menggunakan database. Setelah data tersebut dimasukkan, petugas akan mencetak hardcopynya dan menyimpannya dalam lemari arsip. Pada saat data inventaris tersebut akan diperlukan, petugas akan sibuk mencari arsipnya dengan memeriksa satu per satu rakrak arsip sebagai tempat penyimpanan arsip data inventaris tersebut.

Berdasarkan permasalahan tersebut di atas, maka penulis mencoba merancang suatu sistem informasi yang dapat menghasilkan laporan yang efektif dan efisien tentang data inventaris barang seperti mengetahui data inventaris barang, jumlah pengadaan stock dan jumlah detail aset yang aktif di ruangan pegawai, informasi detail dari pengadaan barang dan mutasi barang ke setiap ruangan pegawai, informasi barang apa saja yang dipakai oleh setiap pegawai, informasi inventaris aset kantor kategori elektronik komputer dan aksesorisnya. Dengan adanya informasi atau laporan keadaan barang ini maka pengambilan keputusan dapat dilakukan lebih cepat dan mempermudah dalam proses back up data.

Berdasarkan latar belakang yang telah diuraikan, maka dapat diidentifikasi permasalahan tersebut:

1. Proses pencatatan inventaris aset kantor di PT. MPM Finance masih dilakukan dengan penggunaan aplikasi MS. Excel yang menyebabkan tercecernya banyak file berbeda dan kesulitan dalam pengelolaan data inventaris aset dan pemakaiannya.

2. Informasi inventaris aset kantor ada yang tidak terdata pada perusahaan dan seorang manager tidak bisa mendapat informasi detail jumlah aset yang ada pada setiap ruangan kerja pegawai maupun ruangan bukan kerja pegawai.

3. Kesulitan dalam membuat laporan atau pemberian informasi kepada atasan tentang kondisi inventaris aset kantor dan pemakaiannya dimana hal ini diperlukan pencatatan ulang dari beberapa file sehingga memakan waktu banyak dalam pembuatan laporan. Kehilangan barang milik kantor yang bisa tidak diketahui oleh manager.

Adapun tujuan penelitian yang ingin dicapai sebagai berikut:

1. Memudahkan dalam pencatatan dan pengelolaan data sehingga dapat meningkatkan efisiensi waktu

2. Dihasilkannya basis data MySQL pada aplikasi pengelolaan inventaris alat kantor di PT. MPM Finance sehingga waktu dan tenaga yang dibutuhkan petugas dalam melayani pelanggan lebih efektif dan efisien

3. Membangun sebuah sistem informasi pengolahan data barang inventaris dimana dapat memberikan informasi yang dibutuhkan seperti informasi penambahan/permintaan 
barang, kondisi barang baik atau rusak, perbaikan barang atau adanya perpindahan/mutasi barang, stock opname kuantitas barang sehingga mempermudah dalam pembuatan laporan yang cepat dan tepat.

Adapun lingkup dan batasan masalah yang dihadapi meliputi:

1. Menampilkan jumlah pengadaan stock dan jumlah detail aset yang aktif di PT. MPM Finance.

2. Menampilkan informasi detail dari pengadaan barang dan mutasi barang ke setiap ruangan pegawai PT. MPM Finance.

3. Menampilkan barang apa saja yang dipakai oleh setiap pegawai PT. MPM Finance.

4. Menampilkan informasi inventaris aset kantor kategori elektronik komputer dan aksesoriesnya.

\section{LANDASAN TEORI}

\section{II.1 Sistem, Informasi dan Sistem Informasi}

Sistem berasal dari bahasa Latin (systema) dan bahasa Yunani (sustema) yang berarti adalah suatu kesatuan yang terdiri komponen atau elemen yang dihubungkan bersama untuk memudahkan aliran informasi, materi atau energi. Menurut O’Brien (O'Brien, James A and Marakas, 2007) sistem merupakan sekelompok komponen yang saling berhubungan dan bekerja sama dimana menerima input serta menghasilkan output dalam proses transformasi yang teratur untuk mencapai tujuan bersama. Sistem semacam ini memiliki tiga komponen atau fungsi yang berinteraksi:

1. Input melibatkan penerimaan dan penyaluran berbagai elemen yang memasuki sistem untuk diproses.

2. Pemrosesan melibatkan proses transformasi yang mengubah input menjadi output.

3. Output melibatkan pemindahan elemen yang telah diproduksi oleh proses transformasi tersebut ke tujuan akhir.

Dari pengertian di atas tadi dapat disimpulkan bahwa sistem merupakan elemen-elemen yang berhubungan yang menghasilkan sesuatu.

Menurut O'Brien (O’Brien, James A and Marakas, 2007) data adalah fakta atau observasi mentah yang biasanya banyak menjelaskan kegiatan tersebut. Sedangkan informasi merupakan data yang telah diubah menjadi konteks yang berarti dan berguna bagi pengguna akhir. Dari pengertian di atas maka informasi adalah data yang dapat dimengerti dan memiliki arti bagi penguna.

Menurut O’Brien (O’Brien, James A and Marakas, 2007) sistem informasi merupakan kombinasi dari hardware, software, manusia, jaringan komunikasi dan sumber daya data yang kemudian mengumpulkan, mengubah dan menyebarkan sistem informasi dalam sebuah organisasi untuk dimanfaatkan sesuai keperluannya. Dari pengertian di atas disimpulkan sistem informasi merupakan gabungan dari beberapa elemen-elemen yang digunakan untuk memberikan informasi yang berarti. Menurut O'Brien (O'Brien, James A and Marakas, 2007) ada tiga alasan mendasar untuk semua aplikasi bisnis dalam teknologi informasi, yaitu:

1. Bermanfaat dalam proses dan operasi bisnis

2. Mendukung bagi pengambilan keputusan para pimpinan dan managernya

3. Mendukung dalam strategi unuk keunggulan kompetitif

\section{II.2 Inventaris Aset}

Inventarisasi merupakan kegiatan dalam menyediakan data atas semua aset yang dimiliki suatu organisasi, baik itu sebagai hasil pembuatan sendiri, pembelian, pertukaran, hadiah, maupun hibah dan akan berkaitan dengan jenis dan spesifikasi aset tersebut, jumlah, sumber, waktu pengadaan, harga, tempat, kondisi dan perubahan-perubahan yang terjadi dimana nantinya berguna untuk mendukung proses pengendalian dan pengawasan logistik serta mendukung efektivitas dan efisiensi dalam upaya pencapaian tujuan organisasi atau perusahaan (Dwiantara, Lukas dan Sumarto, 2005). Menurut Harsono (Harsono, 2005) inventarisasi aset adalah kegiatan-kegiatan yang meliputi pendaftaran, pencatatan dalam daftar inventaris, penyusunan atau pengaturan barang-barang milik negara atau daerah serta melaporkan secara teratur dan tertib pemakaian barang-barang kepada pejabat yang berwenang menurut ketentuan dan tata cara yang berlaku sehingga mempermudah dalam penyajian data kekayaan negara/pemerintah daerah baik barang-barang tetap (misalnya tanah, bangunan, dsb) maupun barangbarang bergerak (mobil, motor, dsb). Jadi inventarisasi aset merupakan suatu kegiatan pencatatan aset atau 
barang sekaligus pengelolaan data aset yang dimiliki organisasi secara profesional demi kelancaran operasionalnya. Sayangnya, keberadaan program inventarisasi belum mendapatkan perhatian yang serius oleh sejumlah organisasi atau perusahaan, sehingga peran dan fungsinya belum begitu terlihat secara nyata. Padahal jika inventaris aset dikelola dengan baik akan memberikan manfaat yang besar bagi kelancaran dan keberhasilan dalam kegiatan suatu organisasi.

Pada dasarnya aset adalah istilah ekonomi dan dengan demikian aset merupakan sesuatu yang mempunyai nilai ekonomis. Secara umum aset adalah barang (thing) atau sesuatu barang (anything) yang mempunyai nilai ekonomi (economic value), nilai komersial (commercial value) atau nilai tukar (exchange value) yang dimiliki oleh badan usaha, instansi atau individu (perorangan). Aset adalah benda yang terdiri dari benda tidak bergerak dan benda bergerak. Barang yang dimaksud meliputi barang yang tidak bergerak (tanah dan atau bangunan) dan barang bergerak (mobil, motor, dsb), baik yang berwujud (tangible) maupun tidak terwujud (intangible), yang tercakup dalam aktiva/kekayaan atau harta kekayaan dari suatu perusahaan, badan usaha, institusi atau individu perorangan. Aset adalah barang yang dalam pengertian hukum disebut benda, yang terdiri dari benda tidak bergerak dan benda bergerak (D et al., 2016). Doli D. Siregar (Siregar, 2004) menyatakan bahwa penilaian aset merupakan suatu proses kerja untuk melakukan penilaian atas aset yang dikuasai. Penilaian aset yang baik dapat memberikan kontribusi terhadap peningkatan kualitas laporan keuangan suatu organisasi atau perusahaan.

\section{II.3 Berbasis Web dan YII-Framework}

Sebuah sistem yang mendukung interaksi pengguna melalui antarmuka berbasis Web adalah yang disebut dengan aplikasi web. Fitur-fiturnya biasanya berupa data persistence, dimana mendukung transaksi dan komposisi halaman Web dinamis yang dapat dipertimbangkan sebagai hibridisasi yaitu antara hypermedia dan sistem informasi. Aplikasi Web adalah bagian dari client-side yang dapat dijalankan oleh browser Web. Client-side mempunyai tanggung jawab untuk pengeksekusian proses bisnis. Interaksi Web dapat dibagi ke dalam tiga langkah yaitu:

1. permintaan

2. pemrosesan

3. jawaban
Halaman Web biasanya dalam format HTML atau XHTML adalah sumber dokumen atau informasi yang dapat dibuat dengan menggunakan berbagai program agar dapat menampilkan suatu informasi di dalam browser (misalnya Java atau PHP). PHP adalah bahasa pemrograman server-side yang didesain spesifik untuk pengembangan aplikasi berbasis web. Banyak kelebihan dari bahasa pemrograman PHP, antara lain pada aspek performa, skalabilitas, portabilitas, open source, dan terutama untuk terkoneksi dan melakukan manipulasi terhadap sebuah basis data (Supaartagorn, 2011). Manajemen basis data dilakukan dengan Structure Query Language (SQL). Structured Query Language atau SQL, adalah nomenklatur pemrograman yang digunakan untuk melakukan sekumpulan operasi (seperti union, intersect, dan minus) dimana untuk mengatur dan mengambil informasi dalam database relasional dengan berdasarkan teori himpunan dan aljabar relasional. Beberapa studi menyatakan bahwa bahasa query database tradisional tidak mudah digunakan untuk pengguna teknologi basis data yang tidak berpengalaman, sebagai konsekuensi karena interaksinya berbasis bahasa tekstual seperti SQL ini (Avensano, L., Canfora, G., De Lucia, A., and Stefanucci, 2002).

Kerangka kerja perangkat lunak (software framework) adalah kerangka kerja untuk mengembangkan aplikasi berbasis website maupun desktop dimana sangat membantu developer dalam menuliskan sebuah sebuah sistem atau subsistem aplikasi dengan lebih terstruktur dan tersusun rapi. Sebuah software framework menyediakan kumpulan kode dasar yang dapat membantu dalam proses pengembangan dan penggabungan komponen yang berbeda pada sebuah perangkat lunak (Paikens \& Arnicans, 2008). Sebuah kerangka kerja pemrograman dapat menyederhanakan proses menyusun kode fungsi program dengan mengurangi kode operasi-operasi yang bersifat pengulangan (Upton, 2007). Karena tujuan framework adalah membantu melakukan aktivitas umum, banyak framework menyediakan pustaka (library) untuk akses database, manajemen data sesi, dsb (BJÖREMO, MARTIN and TRNINIĆ, 2010). Kerangka kerja pemrograman web berbasis bahasa pemrograman PHP-Hypertext Preprocessor memudahkan proses pengembangan aplikasi, membantu menyusun fungsi-fungsi sebuah sistem dengan waktu lebih cepat karena tidak harus menulisnya dari awal. Ini juga dapat meningkatkan kualitas dan stabilitas susunan kode pemrograman 
(Yicheng, 2011). Framework secara signifikan mengurangi waktu, sumber daya, usaha, yang dibutuhkan untuk mengembangkan dan mengelola aplikasi web. Proses pembuatan aplikasi dapat dilakukan dengan lebih cepat dan menghasilkan produk yang berkualitas dan sesuai dengan kebutuhan customer. Developer dapat mengembangkan aplikasi dengan menggunakan komponen-komponen yang telah tersedia dalam framework tersebut. Sehingga, tidak perlu untuk menyusun ulang dari awal kode program. Selain itu, framework adalah arsitektur terbuka yang berbasis standard umum yang digunakan (Shan, T. C., and Hua, 2006).

Dalam desain sistem (design pattern), dikenal dengan baik salah satunya yaitu pendekatan ModelView-Controller. MVC yaitu merupakan pola desain arsitektur website yang terbagi menjadi tiga bagian, yaitu model, view, dan controller. Konsep ini diyakini bisa mengefektifkan proses pembuatan website (Buschmann, F., Meunier, R., Rohnert, H., Sommerlad, P., and Stal, 1996), yang dapat membuat mudah dalam proses pengembangan dan mengelola sebuah aplikasi, karena (Leff, A., and Rayfield, 2001) 2001): (1) tampilan (output) aplikasi dapat berubah drastis tanpa merubah struktur data dan business logic, (2) aplikasi dapat dengan mudah dikelola/digunakan dengan antarmuka (interfaces) yang berbeda-beda, misal adalah multi bahasa, atau pengaturan hak akses user yang berbeda-beda, (3) error atau bug lebih cepat dan mudah ditangani, (4) pemeliharaan atau maintenance lebih mudah. Pendekatan Model-ViewController design pattern adalah cara yang mudah untuk mengembangkan arsitektur sistem perangkat lunak interaktif (Krasner, G. E., and Pope, 1988). Selain MVC, dikenal juga Presentation/Abstraction/Control (PAC), gagasan utamanya adalah untuk memisahkan antarmuka dan data di bawahnya. Presentation-Abstraction-Control (PAC) adalah pola arsitektur perangkat lunak. Ini adalah arsitektur perangkat lunak berorientasi interaksi, dan agak mirip dengan Model-ViewController (MVC) karena memisahkan sistem interaktif menjadi tiga jenis komponen yang bertanggung jawab untuk aspek-aspek tertentu dari fungsionalitas aplikasi. Komponen abstraksi mengambil dan memproses data, komponen presentasi memformat presentasi visual dan audio data, dan komponen kontrol menangani hal-hal seperti aliran kontrol dan komunikasi antara dua komponen lainnya. Berbeda dengan MVC, PAC digunakan sebagai struktur hirarki agen, masing-masing terdiri dari tiga kesatuan bagian presentasi, abstraksi, dan kontrol. Agen-agen (atau kesatuan) berkomunikasi satu sama lain hanya melalui bagian kontrol dari masing-masing kesatuan tersebut. Ini juga berbeda dari MVC karena dalam setiap triad, ia sepenuhnya mengisolasi presentasi (tampilan dalam MVC) dan abstraksi (model dalam MVC). (Coutaz, 1987). Pola ModelView-Controller terbukti efektif untuk menciptakan dan mengorganisir aplikasi modular (Hofmeister, C., Nord, R. L., and Soni, 2000).

YII adalah kerangka kerja pemrograman web umum dimana dapat digunakan untuk mengembangkan semua jenis aplikasi Web yang menggunakan PHP. Karena arsitektur berbasis komponen dan dukungan caching yang canggih, Yii sangat cocok untuk mengembangkan aplikasi skala besar seperti portal, forum, sistem manajemen konten (CMS), proyek e-commerce, layanan web REST, dan sebagainya. YII menyediakan reusabilitas maksimum dalam pemrograman Web dan bisa mengakselerasi proses pengembangan secara signifikan. Nama YII singkatan yes it is, mempunyai pengertian dari easy, efficient dan extensible (mudah, efisien, dan bisa diperluas). Framework Yii sendiri adalah framework yang memiliki konsep penyelesaian suatu masalah tidak lagi dilihat dari bagaimana prosedurnya, tetapi dari objek-objek apa saja yang terkait untuk melakukan penyelesaian masalah tersebut (Pasaribu et al., 2019). Seperti kebanyakan PHP framework, Yii mengimplementasikan pola arsitektur MVC (ModelView-Controller) dalam pemrograman web dan mempromosikan kode organisasi berdasarkan pola itu. MVC bertujuan untuk memisahkan logika bisnis dari pertimbangan antar muka pengguna agar para pengembang bisa lebih mudah mengubah setiap bagian tanpa mempengaruhi yang lain (Sharive, 2013).

Dalam MVC, model menggambarkan informasi (data) dan aturan bisnis; view (tampilan) berisi elemen antar muka pengguna seperti teks, input form; sementara controller mengatur komunikasi antar model dan view. Selain implementasi MVC, Yii juga memperkenalkan front-controller (controller depan), yang disebut Application, yang mengenkapsulasi konteks eksekusi untuk memproses sebuah request. Application mengumpulkan beberapa informasi mengenai request pengguna dan kemudian mengirimnya ke controller yang sesuai untuk penanganan selanjutnya. Diagram berikut memperlihatkan struktur statis sebuah aplikasi Yii menurut website resmi Yii Framework: 


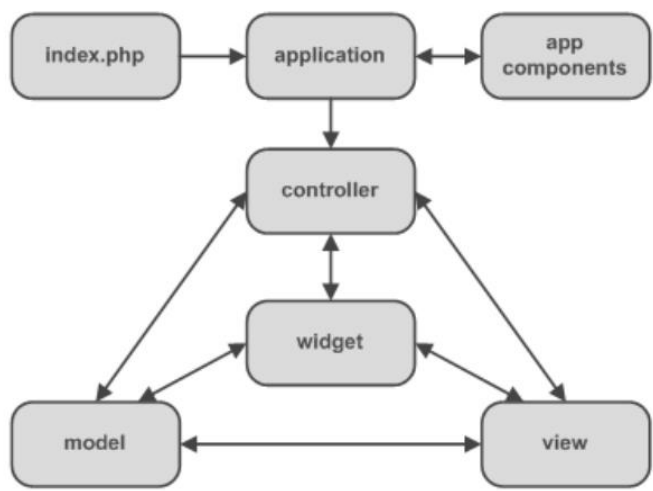

Gambar I. Struktur statis aplikasi Yii (Sharive, 2013).

\section{AnAlisis dan Perancangan}

Bagian analisis dan perancangan sistem informasi berbasis web pengelolaan inventaris aset kantor di PT MPM Finance Bandung berisikan use case diagram, class diagram dan activity-activity diagram. Juga diberikan implementasi dan pengujian sistem yang telah dibuat.

\section{III.1 Pengumpulan Kebutuhan}

Kebutuhan fungsional adalah kondisi, syarat atau kemampuan yang harus dimiliki suatu produk perangkat lunak yang akan dibangun untuk memenuhi apa yang diinginkan atau disyaratkan oleh pengguna. Kebutuhan fungsional juga dikenal sebagai batasan layanan atau fungsi yang ditawarkan sistem. Adapun kebutuhan fungsional ini adalah sebagai berikut: Tabel 1. Kebutuhan Fungsional

\begin{tabular}{|c|c|c|}
\hline No & $\begin{array}{l}\text { Kebutuhan } \\
\text { Fungsional }\end{array}$ & Yang dilakukan aktor \\
\hline 1 & $\begin{array}{l}\text { Sistem harus mampu } \\
\text { mengelola proses } \\
\text { login untuk petugas }\end{array}$ & $\begin{array}{l}\text { Aset management } \\
\text { melakukan proses login }\end{array}$ \\
\hline 2 & $\begin{array}{l}\text { Sistem harus mampu } \\
\text { mengelola data } \\
\text { lokasi/ruangan }\end{array}$ & $\begin{array}{l}\text { Aset management staf } \\
\text { melakukan untuk megelola } \\
\text { ruangan aset berada }\end{array}$ \\
\hline 3 & $\begin{array}{l}\text { Sistem harus mampu } \\
\text { mengelola data } \\
\text { barang }\end{array}$ & $\begin{array}{l}\text { Aset management staf } \\
\text { melakukan untuk mengelola } \\
\text { data aset berada }\end{array}$ \\
\hline
\end{tabular}

Sistem harus mampu
mengelola data
pegawai

5

Sistem harus mampu mengelola transaksi aset

6

Sistem harus mampu mengelola laporan

Aset management staf memudahkan dalam menemukan informasi pegawai dalam suatu ruangan

Aset management staf melakukan pengalokasian aset kantor di setiap ruangan pegawai yang dituju disertai nama pegawai, jabatan, nama ruangan, nama barang, kode barang, kode kategori dan jumlah barang

Aset management staf melakukan pengelolaan laporan informasi aset perusahaan serta detail nama barang dan jumlah aset

Kebutuhan non fungsional adalah yang berhubungan dengan kemudahan pemakaian sistem atau perangkat lunak oleh pengguna, kemudahan dalam pengaksesan sistem, terutama yang berkaitan dengan faktor lokasi pengaksesan, waktu, perangkat ataupun teknologi yang dipakai untuk mengakses, kebutuhan yang terkait dengan keandalan sistem atau perangkat lunak, termasuk soal keamanan sistem, dan kebutuhan yang berhubungan dengan dukungan dalam pemakaian sistem atau perangkat lunak. Teknologi atau perangkat tersebut mencakup perangkat keras, perangkat lunak dan perangkat jaringan.

Tabel 2. Kebutuhan Fungsional

No Kebutuhan Uraian
Non-
Fungsional

$1 \quad$ Operasional

Sistem Operasi: Windows 7/32
bit; Spesifikasi Komputer:
Processor (Pentium 4 / Dualcore
1,6 Ghz), RAM: 512 MB, VGA:
256 MB, Monitor: 14' inch,
Keyboard: Type USB Cable
Standar 101/102 key, Mouse:
Type USB Cable with optical;
Web Browser: Google Chrome,
Internet Explorer \& Mozilla
Firefox; Web Server: Apache;
Database Server: MySQL; Yii
Framework versi 1.1; Sublime
Teks 3; XAMPP versi 1.7.3
dengan support PhpMySQL. 
$2 \quad$ Keamanan
Sistem aplikasi dan database dilengkapi dengan password; dilengkapi dengan CCTV

Usernya adalah petugas / kepala cabang untuk menjalankan aplikasi ini.

\section{III.2 Analisis dan Disain}

Use case diagram untuk mendefinisikan siapa aktor (pengguna) yang terlibat dan aktivitas-aktivitas pengguna sistem serta interaksi antara aktor dengan sistem maupun bagaimana interaksi sistem dengan dunia luar. Diagram ini akan mengetahui fungsi-fungsi yang ada dalam sebuah sistem dan siapa saja (aktor) yang berhak menggunakan fungsi-fungsi tersebut. Berikut ini berisikan use case diagram untuk sistem informasi berbasis web pengelolaan aset kantor di PT MPM Finance Bandung:

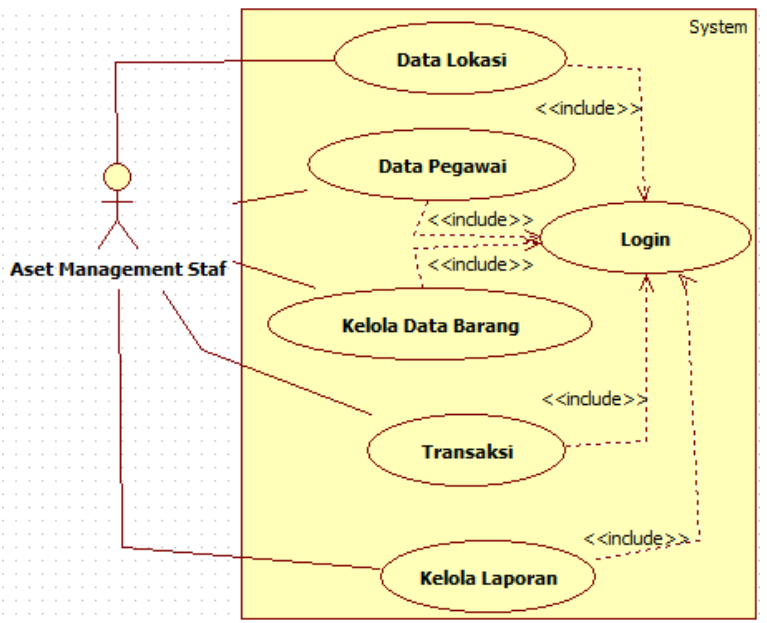

Gambar II. Use Case Diagram

Class Diagram merupakan suatu cara memetakan struktur sistem dengan memodelkan kelas, attribut, operasi serta hubungan antar objek seperti asosiasi, pewarisan dan lain-lain dalam sebuah sistem. Berikut ini berisikan class diagram untuk sistem informasi berbasis web pengelolaan aset kantor di PT MPM Finance Bandung:

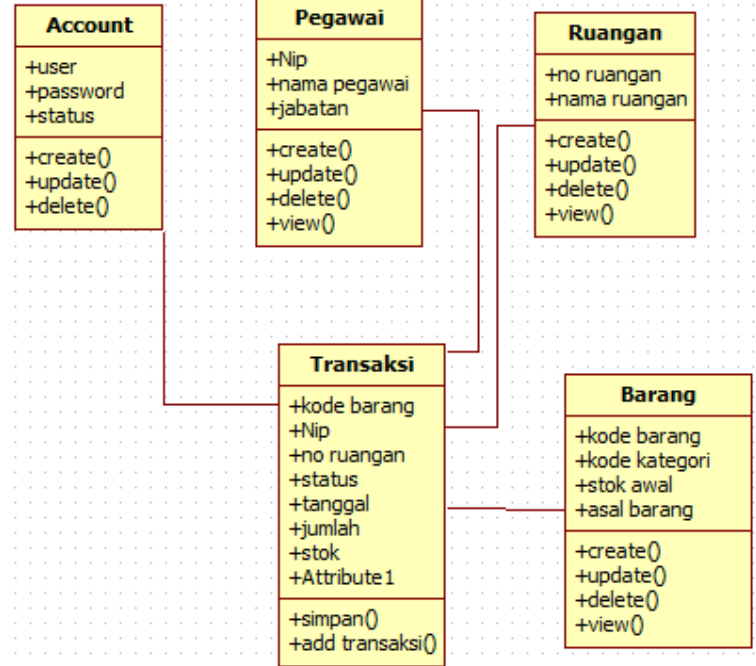

Gambar III. Class Diagram

Activity diagram atau diagram aktivitas yaitu salah satu jenis diagram pada UML yang dapat memodelkan proses-proses apa saja yang terjadi pada sistem yaitu runtutan proses dari suatu sistem digambarkan secara vertikal. Activity diagram merupakan pengembangan dari Use Case yang memiliki alur aktivitas. Alur atau aktivitas berupa bisa berupa runtutan menu-menu atau proses bisnis yang terdapat di dalam sistem tersebut. Berikut ini diberikan beberapa activity diagram sistem informasi berbasis web pengelolaan aset kantor di PT MPM Finance Bandung:

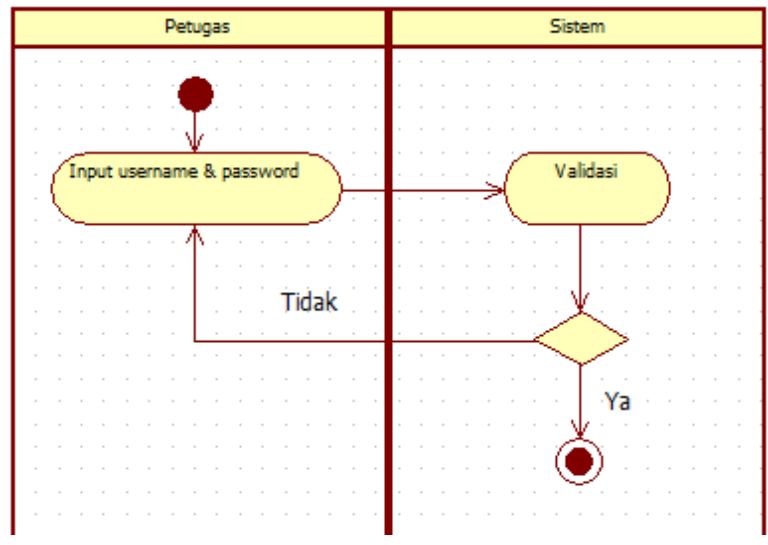

Gambar IV. Activity Diagram Login 


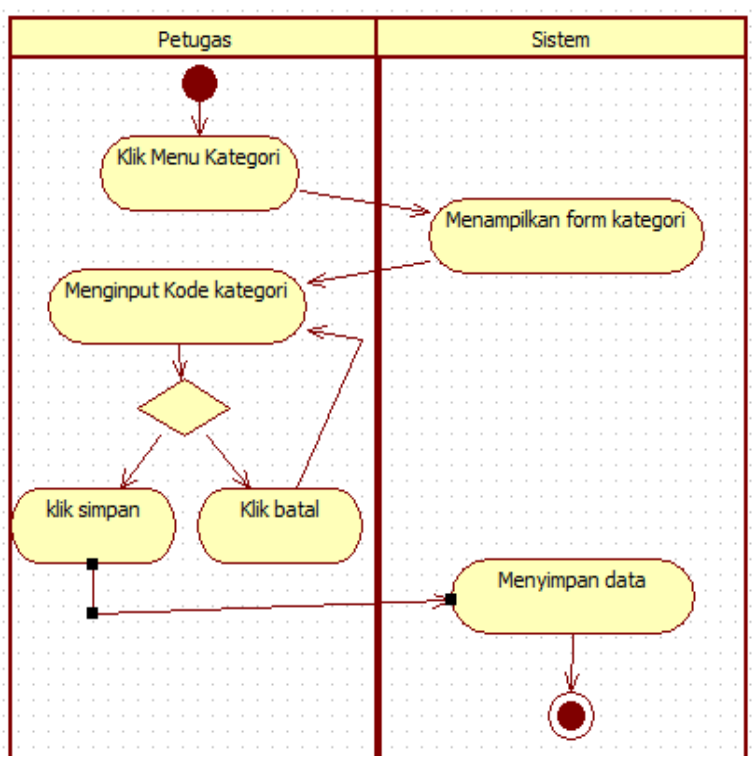

Gambar V. Activity Diagram Kategori

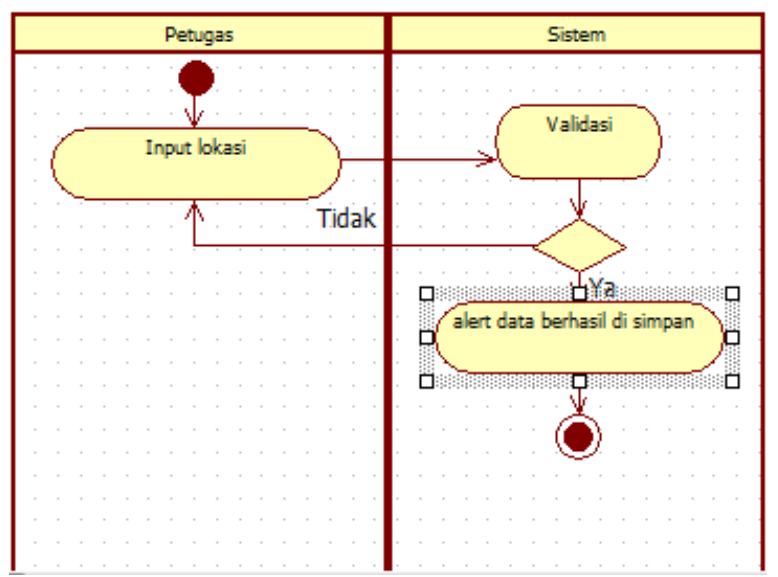

Gambar VI. Activity Diagram Data Lokasi

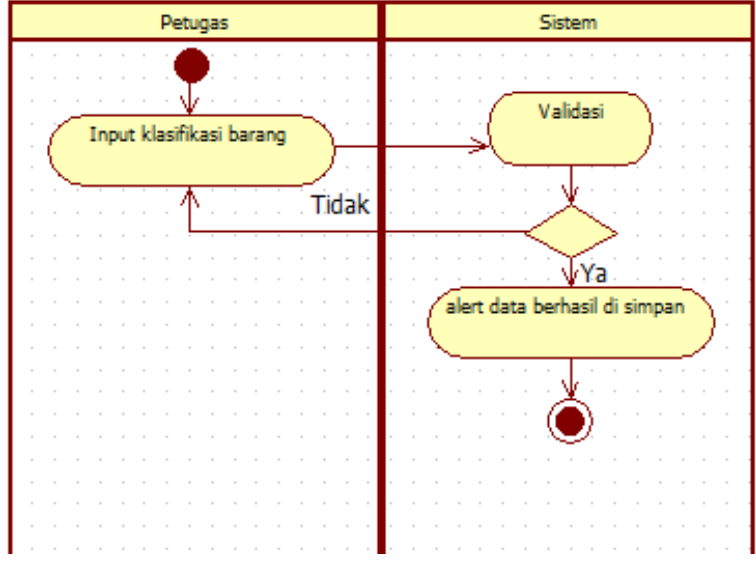

Gambar VII. Activity Diagram Data Barang

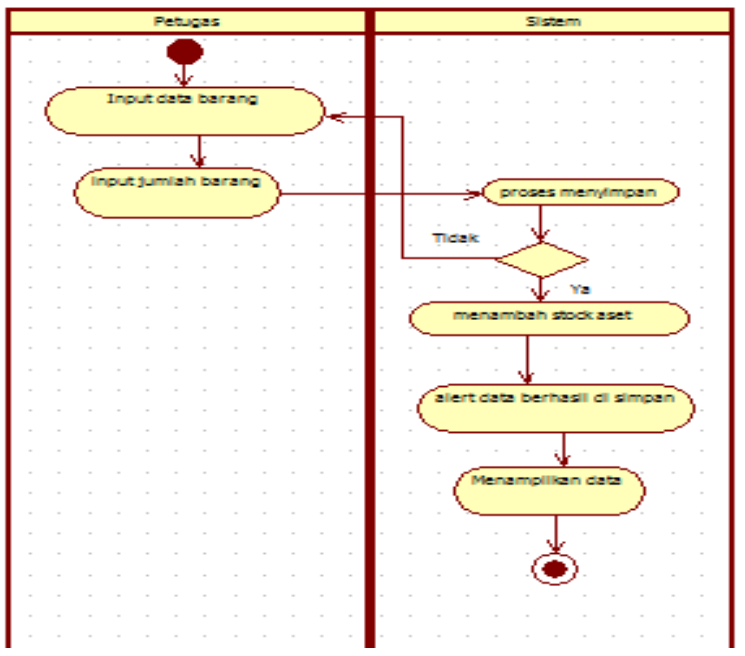

Gambar VIII. Activity Diagram Kelola Data Barang 


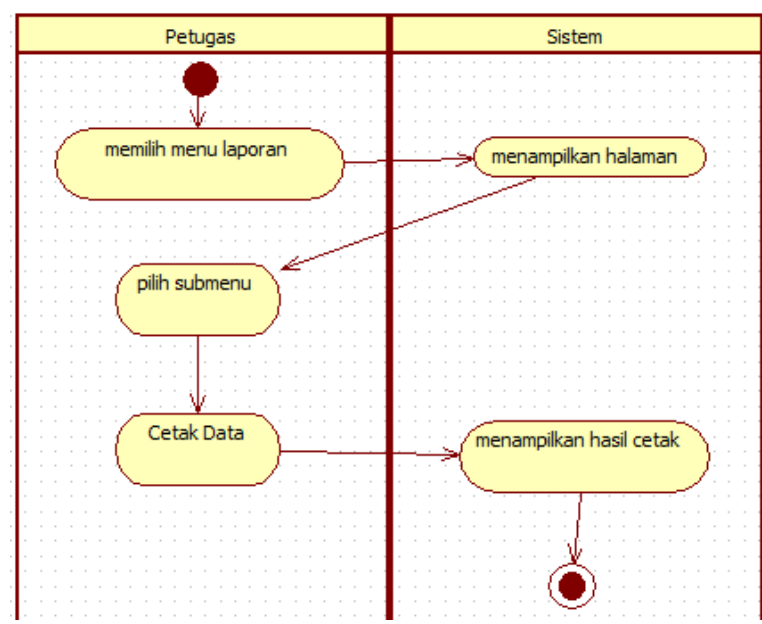

Gambar IX. Activity Diagram Kelola Laporan

\section{III.3 Implementasi Antar Muka}

Pada tahap implementasi ini akan dijelaskan beberapa hasil dari pembuatan sistem informasi berbasis web pengelolaan aset kantor di PT MPM Finance Bandung. Gambar X halaman Login berfungsi agar petugas/admin dapat mendaftarkan diri. Adapun uraiannya: buka sistem informasi berbasis web pengelolaan aset kantor di PT MPM Finance Bandung, pilih menu Login, isi semua field yang sudah disediakan. Halaman Login bisa dilihat pada Gambar IV:

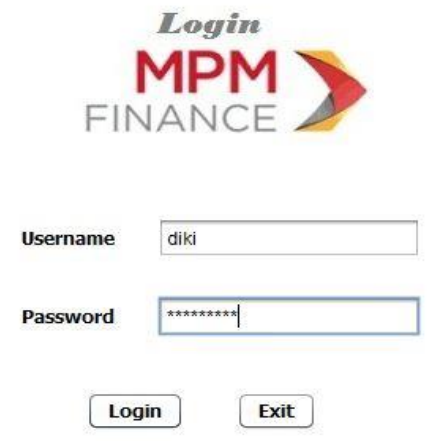

Gambar X. Login

Gambar XI adalah tampilan menu utama yang berguna untuk input/update/delete aset, input/update/delete ruangan, input/update/delete pegawai, membuat laporan dan lainnya. Cara penggunaannya adalah aset management staf bisa melakukan input/update/delete aset, ataupun bisa melihat data aset, kemudian jika menambahkan aset, arahkan kursor ke tombol tambah aset dan isi data yang telah disediakan.

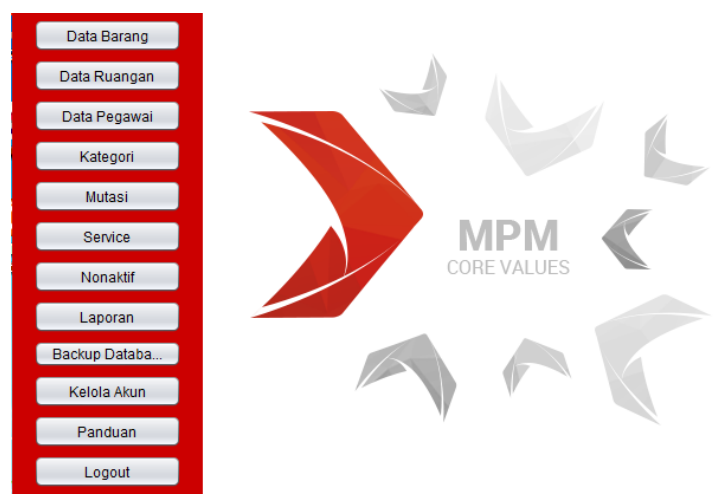

Gambar XI. Halaman Menu Utama

Pada halaman menu lokasi untuk menambahkan ruangan aset berada ataupun melihat data ruangan/lokasi. Cara penggunaannya adalah aset management staf melakukan tambah data ataupun bisa melihat data lokasi, kemudian jika menambah ruangan klik input ruangan, lalu masukan no ruangan dan nama ruangan, dan klik button simpan. Apabila berhasil, data akan tersimpan di database. Berikut ini ditunjukkan halaman menu lokasi:

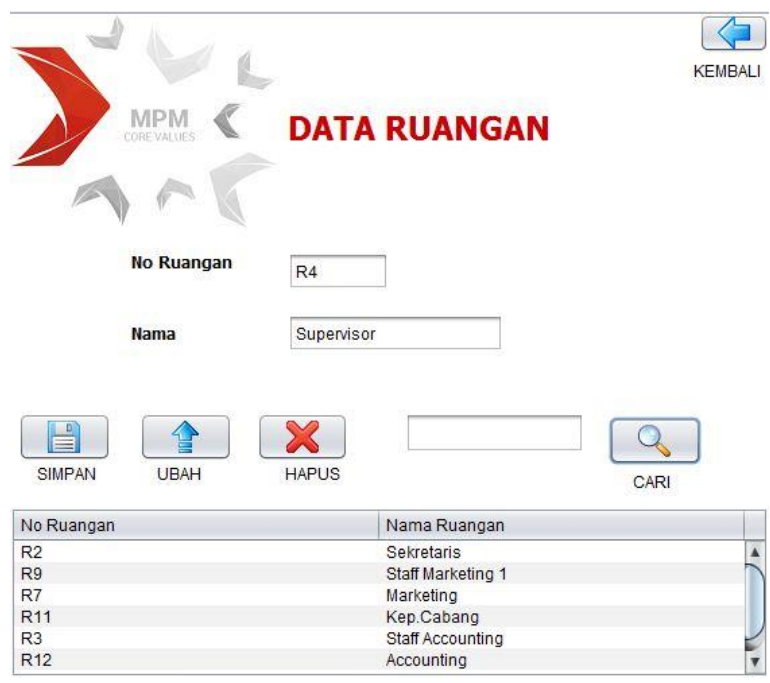

Gambar XII. Halaman Menu Lokasi
Johni S Pasaribu

Jurnal Ilmiah Teknologi Informasi Terapan

Volume 7, No 3, 15 Agustus 2021 
Menu kelola laporan berguna untuk untuk membuat data laporan informasi aset perusahaan, aset/barang yang dialokasikan, serta detail nama barang dan jumlah aset. Pada form ini membuat laporan bisa berdasarkan Transaksional, Grouping dan Parameter. Untuk memudahkan pengelompokan data yang dibutuhkan sebagai informasi, pilih berdasarkan Kode barang, NIP Pegawai, Ruangan. Preview, kemudian jika akan diimport kedalam bentuk laporan dan jika akan dicetak. Halaman menu kelola laporan bisa dilihat pada gambar XIII:

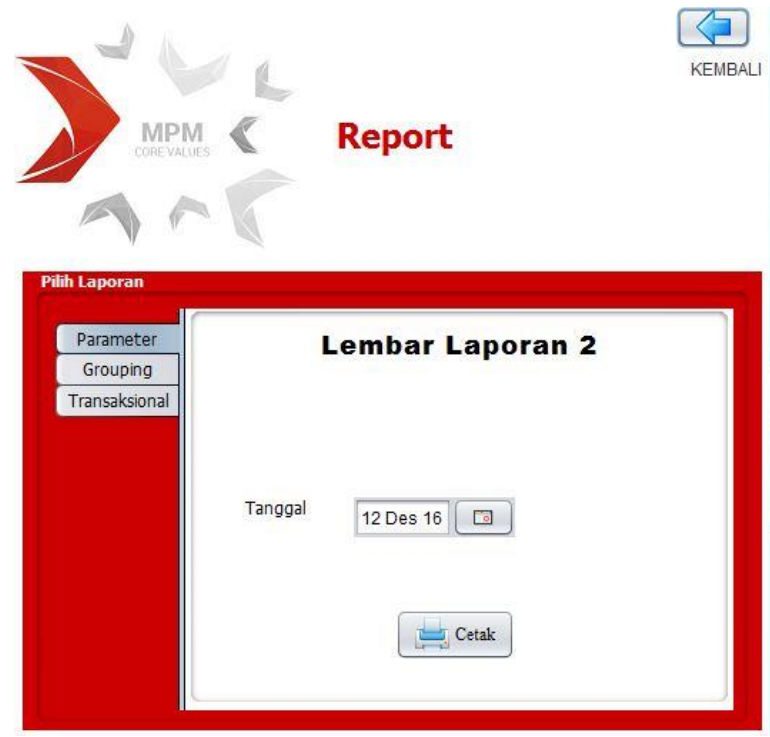

Gambar XIII. Halaman Menu Kelola Laporan

Selanjutnya pada tampilan menu help berguna untuk memberikan informasi langkah-langkah penggunaan aplikasi seperti: input data barang, tambah akun, transaksi, input data pegawai, input nomor ruangan, laporan dan logout. Pada setiap menu tersebut akan diberikan cara penggunaannya. Menu Help dapat dilihat pada Gambar XIV:

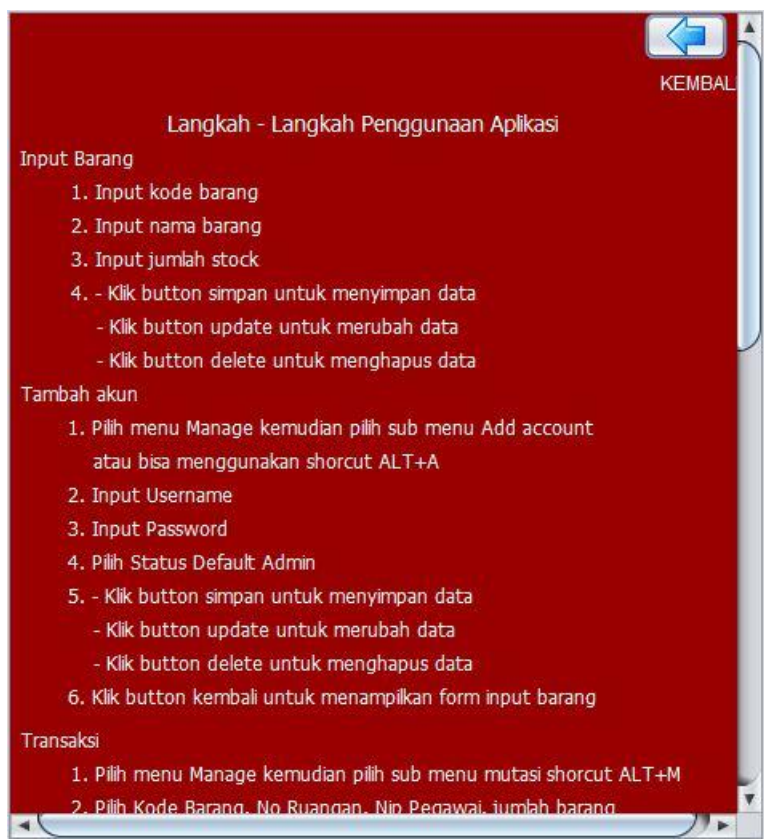

Gambar XIV. Halaman Menu Help

Menu input berguna untuk melakukan input data barang. Form isian barang terdiri dari kode barang/pcs, kode kategori, asal barang dan stok barang Kode kategori diisi sesuai dengan yang sudah tersedia pada form kategori. Halaman menu input barang bisa dilihat pada gambar $\mathrm{XV}$ :

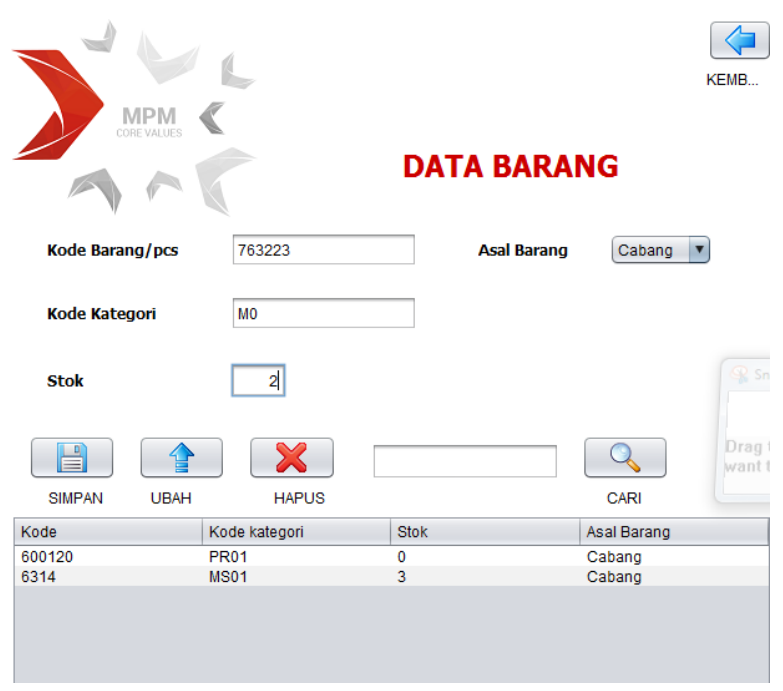

Gambar XV. Halaman Menu Input Barang 
Halaman input pegawai berguna melihat data pegawai atau melakukan input pegawai. Inputan detail pegawai dan NIP otomatis dari sistem setelah diklik tombol simpan. Dapat mengedit dan menghapus data pegawai yang sudah tidak bekerja pada perusahaan. Halaman menu input anggota dapat dilihat pada Gambar XVI:

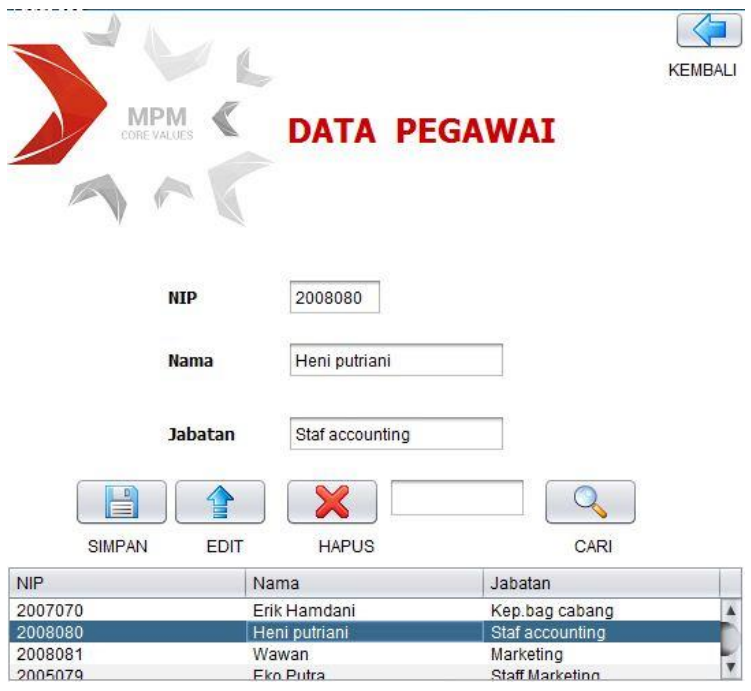

Gambar XVI. Halaman Menu Input Pegawai

Halaman kelola akun berguna untuk pengelolaan admin dalam mengelola aplikasi. Hanya menampilkan username dan statusnya sebagai admin. Dapat mengupdate password. Berikut ini ditunjukkan menu kelola akun:

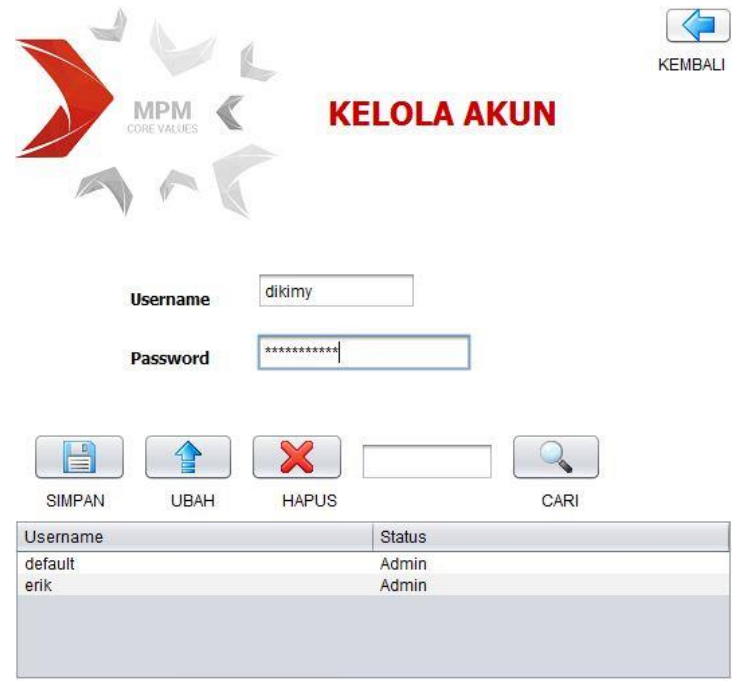

Gambar XVII. Halaman Menu Kelola Akun
Pada tampilan menu mutasi (transaksi) berguna untuk melakukan pengalokasian aset kantor yang akan dipindah tempatkan. Dengan memasukkan inputan kode barang untuk memproses pengalokasian baru. Berikut ini ditunjukkan menu mutasi:

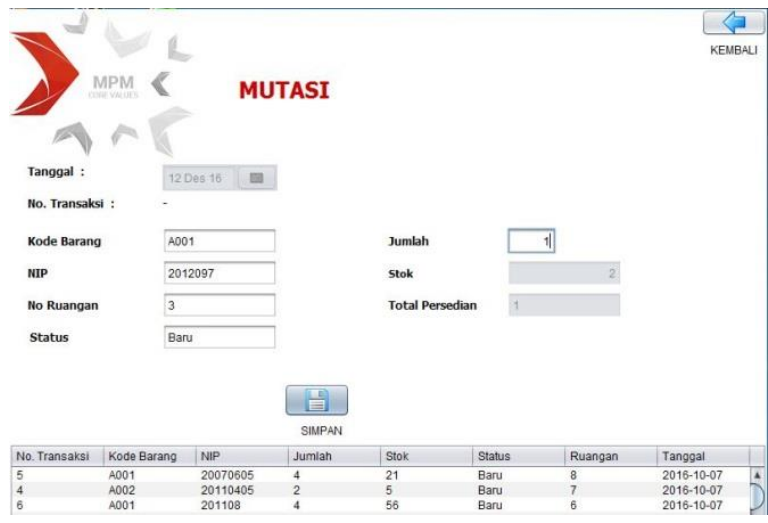

Gambar XVIII. Halaman Menu Mutasi

Pada tampilan menu inventaris opsional berguna untuk mendata aset alat kantor yang rusak dan perlu diperbaiki. Dan jika sudah diservis dan berfungsi kembali maka barang/aset tersebut akan dikembalikan ke data barang dan stok nya pun kembali bertambah. Berikut ini ditunjukkan menu inventaris opsional:

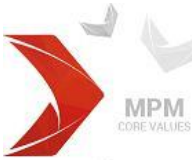

KEMBALI

\section{INVENTARIS OPSIONAL}

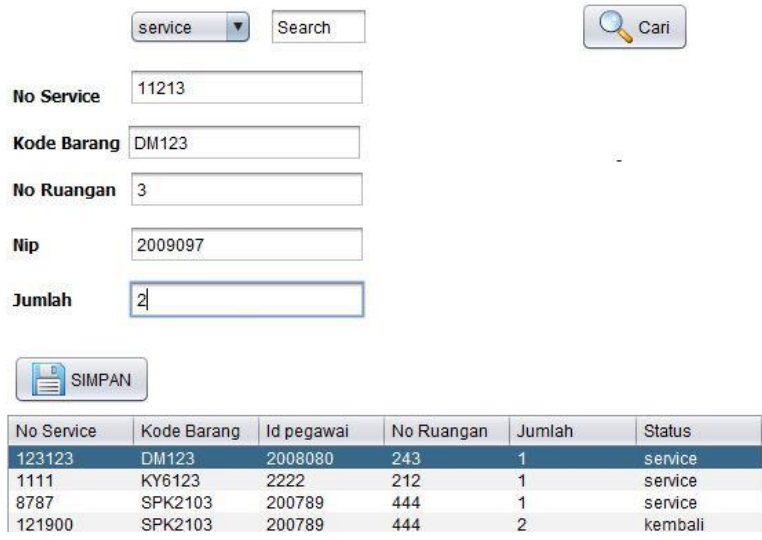

Gambar XIX. Halaman Menu Inventaris Opsional 
Pada halaman menu non aktif berfungsi jika seandainya alat inventaris yang sudah tidak dapat dioperasikan atau jika tidak digunakan maka data barang tersebut akan terhapus dari stok barang Berikut ini ditunjukkan Form Menu Non Aktif:

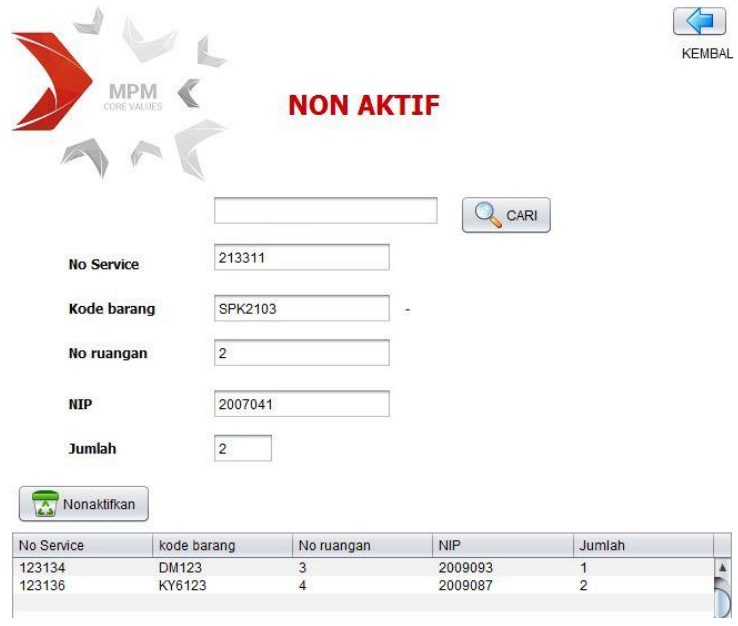

Gambar XX. Halaman Menu Non Aktif

Pada halaman menu kategori berfungsi untuk mengelompokkan data aset yang jenis nya sama untuk mempermudah pencarian data. Yaitu dengan menginput nama jenis barang tersebut maka kode kategori akan terbuat otomatis lalu inputkan juga merek dari barang tersebut. Berikut ini ditunjukkan Form Menu Kategori:

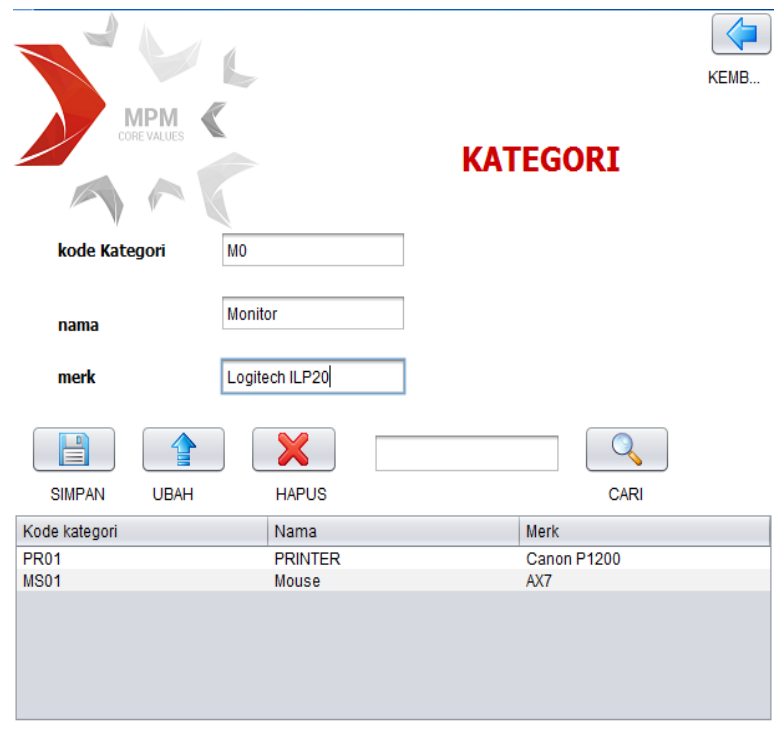

Gambar XXI. Halaman Menu Kategori

\section{KESIMPULAN DAN SARAN}

Berdasarkan perancangan dan implementasi yang telah dibuat, maka kesimpulan dari topik Perancangan Sistem Informasi Berbasis Web Pengelolaan Aset Kantor di PT. MPM Finance Bandung adalah sebagai berikut:

1. Dengan adanya perangkat lunak ini maka PT MPM Finance Bandung lebih mudah dalam pencatatan dan pengelolaan data aset kantor sehingga waktunya lebih efisien.

2. Aplikasi inventaris ini memberikan solusi permasalahan yaitu membantu dalam melakukan konfigurasi, pendataan, penjumlahan dan status serta pembuatan laporan informasi aset perusahaan tersebut.

3. Aplikasi inventaris ini membantu seorang pimpinan dalam pendataan aset alat kantor sehingga menjadi lebih akurat.

4. Aplikasi inventaris ini dapat menyimpan data aset perusahaan sehingga tidak akan hilang.

5. Aplikasi inventaris ini dapat mengetahui letak atau lokasi aset perusahaan secara cepat.

Adapun saran-saran yang dapat digunakan untuk pengembangan perangkat lunak yang sudah dibuat sebagai berikut:

1. Memberikan User Guide secara detail kepada admin / petugas sehingga tidak terjadi kesalahan dalam pengoperasian aplikasi ini.

\section{REFERENSI}

Avensano, L., Canfora, G., De Lucia, A., and Stefanucci, S. (2002). Understanding SQL through Iconic Interfaces. Computer Software and Applications Conference (COMPSAC). https://www.academia.edu/29821332/Understan ding_SQL_through_iconic_interfaces

BJÖREMO, MARTIN and TRNINIĆ, P. (2010). Evaluation of web application frameworks [Chalmers University of Technology, University of Gothenburg]. https://publications.lib.chalmers.se/records/fullt ext/123847.pdf

Buschmann, F., Meunier, R., Rohnert, H., Sommerlad, P., and Stal, M. (1996). Pattern-Oriented
Johni S Pasaribu

Jurnal Ilmiah Teknologi Informasi Terapan

Volume 7, No 3, 15 Agustus 2021 
Software Architecture: A System of Patterns (1st ed.). John Wiley \& Sons, Inc. https://wiki.sch.bme.hu/images/9/98/Sznikak_je gyzet_Pattern-Oriented-SA_vol1.pdf

Coutaz, J. (1987). PAC, an Object-Oriented Model for Dialog Design. Proceedings of HumanComputer Interaction (INTERACT), 431-436. https://books.google.co.id/books?id=j7ejBQAA QBAJ\&pg=PA429\&lpg=PA429\&dq=Coutaz, $+\mathrm{J}$ .,+1987,+PAC,+an+Object-

Oriented+Model+for+Dialog+Design,+Proceedi ngs+of+Human-

Computer+Interaction+(INTERACT),+Universi ty+of+Stuttgart,+Federal+Republic+of+German $\mathrm{y},+$ September $+1 \&$ source $=$ bl\&ots $=$ RgDD9COH 60\&sig=ACfU3U3_qqoWShKMeez6ZBbwRh0 HqpUgQA\&hl=en\&sa $=X \& v e d=2 a h U K E w j S x a$ vIp_HxAhWZf30KHU4WDkEQ6AEwAXoEC AIQAw\#v=onepage \&q=Coutaz $\% 2 \mathrm{C} \quad \mathrm{J} . \% 2 \mathrm{C}$ 1987\%2C PAC\%2C an Object-Oriented Model for Dialog Design\%2C Proceedings of HumanComputer Interaction (INTERACT)\%2C University of Stuttgart\%2C Federal Republic of Germany\%2C September 1\&f=false

D, D., Mukhlisin, \& Siregar, S. (2016). Otonomi dan Pengelolaan Aset Daerah. Sinergi Manajemen Aset (SIMA).

Dwiantara, Lukas dan Sumarto, R. H. (2005). Manajemen Logistik Pedoman Praktis Bagi Sekretaris dan Staf Administrasi (S. R (ed.); 2nd ed.). Gramedia.

Harsono. (2005). Administrsi Perkantoran 1. Alqaprint.

Hofmeister, C., Nord, R. L., and Soni, D. (2000). Applied Software Architecture (1st ed.). AddionWesley.

Krasner, G. E., and Pope, S. T. (1988). A Cookbook for Using the Model-View-Controller UserInterface Paradigm in Smalltalk-80. Journal of Object-Oriented Programming, 26-49. https://www.ics.uci.edu/ redmiles/ics227-

SQ04/papers/KrasnerPope88.pdf

Leff, A., and Rayfield, J. T. (2001). Web-application Development using the Model/View/Controller Design Pattern. Proceedings Fifth IEEE International Enterprise Distributed Object Computing Conference, 118-127. https://ieeexplore.ieee.org/document/950428
O'Brien, James A and Marakas, G. M. (2007). Enterprise Information Systems (13th ed.). McGraw Hill.

Pasaribu, J. S., Alim, A., \& Almamalik, L. (2019). Information System Based on Website Application as Implementation of Disclosure of Public Information at Diskominfo Kabupaten Bandung. Journal of Physics: Conference Series, 1179(1). $\quad$ https://doi.org/10.1088/17426596/1179/1/012032

Shan, T. C., and Hua, W. W. (2006). Taxonomy of Java Web Applications Frameworks. IEEE International Conference on E-Business Engineering (ICEBE'06), 1, 378-385. https://www.computer.org/csdl/proceedingsarticle/icebe/2006/26450378/12OmNrAMF21

Sharive. (2013). YII Framework: Menguasai PHP Terbaik. Lokomedia.

Siregar, D. D. (2004). Manajemen Aset. PT. Gramedia Pustaka Utama.

Supaartagorn, C. (2011). PHP Framework for Database Management Based on MVC Pattern. International Journal of Computer Science \& Information Technology (IJCSIT), 3(2), 251258.

http://airccse.org/journal/jcsit/0411csit19.pdf

Upton, D. (2007). CodeIgniter for Rapid PHP Application Development (1st ed.). Packt Publishing.

Yicheng, L. (2011). Development of a Blog System using CodeIgniter Framework [Oulu University of Applied Sciences, Oulu, Finland]. https://www.theseus.fi/bitstream/handle/10024/ 32076/Li_Yicheng.pdf?sequence=1\&isAllowed $=\mathrm{y}$ 